\title{
Perioperative Risk Factors for Intraoperative Hypothermia in Adult Patients Undergoing Elective Surgery at a National Referral Hospital in Bhutan: A Prospective Observational Study
}

\author{
Kinley Zangmo, M.D. ${ }^{1}$ S Sunisa Chatmongkolchart, M.D. ${ }^{2}$, Pasuree Sangsupawanich, M.D., Ph.D. ${ }^{3}$ \\ ${ }^{1}$ Central Regional Referral Hospital, Gelephu, 31101, Bhutan. \\ ${ }^{2}$ Department of Anesthesiology ${ }^{3}$ Department of Pediatrics, Faculty of Medicine, Prince of Songkla University, \\ Hat Yai, Songkhla 90110, Thailand. \\ Received 31 May 2019 • Revised 19 July 2019 • Accepted 6 September 2019 • Published online 2 October 2019
}

\section{Abstract:}

Objective: Intraoperative hypothermia is commonly encountered in anesthetic practice. It is related to several risk factors and can lead to various adverse events. It is important to detect it early and prevent the complications related to it. This study was done to identify incidence and perioperative risk factors of intraoperative hypothermia at a national referral hospital in Bhutan.

Material and Methods: A prospective observational study was conducted in adult patients who underwent elective surgery lasting more than 30 minutes. Patient characteristics, incidence of hypothermia, and any interventions for treatment of hypothermia during the operation were recorded. Intraoperative hypothermia was defined as a core body temperature less than $36{ }^{\circ} \mathrm{C}$ measured with an esophageal probe.

Results: Data were obtained from 91 patients with a mean ( \pm standard deviation; S.D.) age of 42.3 (17.2) and American Society of Anesthesiologists (ASA) scores of 1 and 2 in $62.6 \%$ and $37.4 \%$ of the patients, respectively The patients underwent elective surgery with a mean (S.D.) duration of 73.24 (48.1) minutes and a mean (S.D.) duration of anaesthesia of 80.9 (49.2) minutes. The incidence of intraoperative hypothermia was $61.5 \%$ (56/91). Preoperative heart rate more than 80 beats per minute [hazard ratio $(\mathrm{HR}) 0.45,95 \%$ confidence interval $(\mathrm{Cl}), 0.26-0.77$ ] was a protective factor and duration of anesthesia more than 60 minutes (HR 1.82, 95\% Cl, 0.98-3.38) was a risk factor for intraoperative hypothermia. Conclusion: Patients with a preoperative heart rate less than 80 beats per minute and undergoing duration of anesthesia more than 60 minutes should be assessed from the preoperative period and continuously monitored throughout the intraoperative period.

Keywords: core body temperature, complications from hypothermia, intraoperative hypothermia, intraoperative monitoring, perioperative care, perioperative risk factors

Contact: Kinley Zangmo, M.D.

Central Regional Referral Hospital, Gelephu, 31101, Bhutan.

E-mail: gtkinley@gmail.com
J Health Sci Med Res 2019;37(4):313-320 doi: 10.31584/jhsmr.201966 www.jhsmr.org 


\section{Introduction}

One of the common problems encountered in anesthesia is intraoperative hypothermia which is defined as a core body temperature less than $36{ }^{\circ} \mathrm{C}$. The incidence has been reported as high as 30.0 to $50.0 \% .^{1-3}$ Intraoperative hypothermia is associated with complications that include postoperative shivering, intraoperative bleeding, delayed wound healing, wound infection, and anesthetic problems such as delayed awakening from anesthesia. ${ }^{4-8}$ Thus, it is important to identify intraoperative hypothermia early to prevent these complications.

The cause and effect of inadvertent intraoperative hypothermia has been extensively studied and many guidelines $^{9-11}$ have been developed. These guidelines suggest continuous monitoring of the core body temperature of all patients undergoing surgery. In a survey study ${ }^{12}$, authors found that hypothermia is recurrent in anesthetic surgical procedures and it is neither valued nor treated as it should. Although guidelines were developed for proper management of hypothermia, implementation is still a problem. It is not a standard of care in many settings in the world. ${ }^{12,13}$

Several factors related to the patient, surgical procedure, and anesthesia were shown to be associated with intraoperative hypothermia. ${ }^{1,3,14-21}$ Different studies found different predictive factors for intraoperative hypothermia.

Bhutan is a high altitude country located 2,000 to 3,000 meters above sea level with a cold climate. We postulated that patients who undergo surgeries at this altitude and in a cold climate may be more vulnerable to intraoperative hypothermia. Therefore, this study was conducted to identify the incidence and perioperative risk factors of intraoperative hypothermia in adult patients undergoing elective surgery lasting more than 30 minutes in Bhutan.

\section{Material and Methods}

We conducted a prospective observational study at the Jigme Dorji Wangchuck National Referral Hospital in Bhutan from August to November 2017. The study was approved by the Human Research Ethics Committee, Faculty of Medicine, Prince of Songkla University, Thailand and the Research Ethics Board of Health, Ministry of Health, Bhutan. Informed written consents were taken from the participants prior to their enrolment in the study. The trial was registered prior to patient enrolment at clinicaltrials.in.th/. This manuscript is written in adherence to the CONSORT (STROBE) guidelines.

The inclusion criteria were adult patients 18-75 years old, American Society of Anesthesiologists (ASA) physical classification 1 to 3 , and underwent elective surgery lasting more than 30 minutes regardless of anesthetic technique. The exclusion criteria were emergency cases, patients with a history of thyroid disease, malignant hyperthermia, malignant neuroleptic syndrome, patients with preoperative hyperthermia (core body temperature $>37.5^{\circ} \mathrm{C}$ ), and patients with difficulty in temperature monitoring access.

The recorded data included patient characteristics and risk factors that included age, sex, body weight, body mass index, preoperative body temperature, preoperative blood pressure, preoperative heart rate, type of case (outpatient or inpatient), type and duration of operation, technique of anesthesia, duration of anesthesia, operating room temperature, and any interventions for treatment of hypothermia during the operation.

The recruited patients were monitored from the preoperative period at the ward. Preoperative core body temperature was measured with an ear thermometer (Medicare infrared ear and forehead thermometer Model $\mathrm{HW}-1$, China) and a digital vital signs monitor (Mindray, 
VS-800, China) was used to monitor preoperative blood pressure and heart rate.

In the intraoperative period, the patient's core body temperature, blood pressure, and heart rate were recorded at the time of induction of anesthesia and at the start of surgery. The core body temperature was measured with an esophageal probe (Mindray monitor MR402B, China). The room temperature was measured with a room thermometer (KIJ Thermometer, Max-Min Thermometer, Thailand). The intraoperative recordings were done every 15 minutes in the first hour of surgery and then every 30 minutes after the first hour until the end of surgery and the patient was sent to the recovery room.

Intraoperative hypothermia was defined as core body temperature less than $36{ }^{\circ} \mathrm{C}$ at any point of time during the intraoperative period measured by an esophageal probe. All patients were monitored until the end of surgery. Patients who developed intraoperative hypothermia were managed accordingly to prevent further decrease in body temperature. Others were monitored until the end of surgery to detect intraoperative hypothermia. During the intraoperative period, the hypothermic patients were treated sequentially with cotton blankets, forced-air warmer, warmed intravenous fluids, and a plastic cover over the patient's head area wherever appropriate. In addition, the operating room temperature was monitored and adjusted accordingly to maintain the optimum room temperature to keep the patients warm.

The sample size was calculated based on the previous reports using the formula for two proportions. We used the proportion of patients with a low preoperative core body temperature in the hypothermic group (33.0\%) and the proportion of patients with low preoperative core body temperature in the normal group $(20.0 \%)$ to detect a difference of $13.0 \%$ of hypothermia with a power of 0.8 and alpha level 0.05 . Thus, the total number of participants needed was 174. Data were collected from 174 patients who underwent elective surgery but the final analysis was done in 91 patients who had their core body temperature monitored by an esophageal probe. We excluded 83 patients who had regional anesthesia and whose core body temperature measurement were done by the tympanic membrane thermometer because the esophageal probe and tympanic membrane thermometer gave inconsistent readings and could have led to measurement bias.

Data analysis was done with the R program version 3.1.2. Survival analysis was done to find the time to hypothermia in patients who developed intraoperative hypothermia. In patients who developed intraoperative hypothermia we analyzed until the patients developed hypothermia and in patients who had normal intraoperative core body temperature we analysed until the end of the operation. Descriptive data are summarized as percentage and proportion. Continuous data are summarized as mean ( \pm standard deviation; S.D.) or median and interquartile range as appropriate. Univariate analysis was done using the log-rank test. The final model was predicted with multivariate Cox proportional hazards regression model. Multicollinearity was checked using a variance inflation factor.

\section{Results}

Data were obtained from 91 patients with a mean (S.D.) age of 42.3 (17.2) years (range 18-75 years) and ASA scores of 1 and 2 in $62.6 \%$ and $37.4 \%$ of the patients, respectively. The patients underwent elective surgery with a mean (S.D.) duration of 73.2 (48.1) minutes and a mean (S.D.) duration of anesthesia of 80.9 (49.2) minutes. The incidence of intraoperative hypothermia was $61.5 \%$ (56/91). The general characteristics of the patients are presented in Table 1. The lowest intraoperative core body temperature in the normothermia group was $36.0{ }^{\circ} \mathrm{C}$ and $34.1^{\circ} \mathrm{C}$ in the hypothermia group. 
The univariate analysis of the perioperative risk factors for intraoperative hypothermia is presented in Table 2. Multivariate Cox proportional hazards regression showed that preoperative heart rate more than 80 beats per minute was a protective factor and duration of anesthesia more than 60 minutes was a risk factor for intraoperative hypothermia (Table 3). The median time to develop intraoperative hypothermia was 45 minutes.

Table 1 Baseline characteristics of the patients in the normothermia and hypothermia groups

\begin{tabular}{|c|c|c|}
\hline Characteristic & Normothermia & Hypothermia \\
\hline Characteristic & $\mathrm{n}=35$ & $n=56$ \\
\hline Age (year), median (IQR) & $38.0(27.5,57.0)$ & $39.5(25.0,58.2)$ \\
\hline \multicolumn{3}{|l|}{ Sex } \\
\hline Male & $13(37.1)$ & $23(41.1)$ \\
\hline Female & $22(62.9)$ & $33(58.9)$ \\
\hline Body mass index $\left(\mathrm{kg} / \mathrm{m}^{2}\right)$, mean (S.D.) & $24.4(4.7)$ & $23.0(4.1)$ \\
\hline \multicolumn{3}{|l|}{ ASA classification } \\
\hline 1 & $21(60.0)$ & $36(64.3)$ \\
\hline 2 & $14(40.0)$ & $20(35.7)$ \\
\hline Preoperative temperature $\left({ }^{\circ} \mathrm{C}\right)$, mean (S.D.) & $36.5(0.4)$ & $36.4(0.3)$ \\
\hline Preoperative SBP (mm Hg), mean (S.D.) & $117.6(10.6)$ & $121.6(11.1)$ \\
\hline Preoperative HR (bpm), mean (S.D.) & $84.4(6.9)$ & $79.8(9.6)$ \\
\hline \multicolumn{3}{|l|}{ Case } \\
\hline Outpatient & $1(2.9)$ & $0(0.0)$ \\
\hline Inpatient & $34(97.1)$ & $56(100.0)$ \\
\hline \multicolumn{3}{|l|}{ Type of anesthesia } \\
\hline General anesthesia (GA) & $32(91.4)$ & $54(96.4)$ \\
\hline Combined $\mathrm{GA}$ and RA & $3(8.6)$ & $2(3.6)$ \\
\hline \multicolumn{3}{|l|}{ Type of surgery } \\
\hline General surgery & $6(17.1)$ & $27(48.2)$ \\
\hline Gynecology & $7(20.0)$ & $4(7.1)$ \\
\hline Orthopedics & $10(28.6)$ & $12(21.4)$ \\
\hline ENT & $4(11.4)$ & $6(10.7)$ \\
\hline Others & $8(22.9)$ & $7(12.5)$ \\
\hline Intraoperative room temperature $\left({ }^{\circ} \mathrm{C}\right)$, mean (S.D.) & $22.9(1.5)$ & $23.1(1.4)$ \\
\hline Duration of operation (min), median (IQR) & $50(35.0,67.5)$ & $65(53.8,101.2)$ \\
\hline Duration of anesthesia (min), median (IQR) & $55(40.0,77.5)$ & $70.0(63.8,110.0)$ \\
\hline Infusion of unwarmed IV fluid & $35(100.0)$ & $54(96.4)$ \\
\hline
\end{tabular}

IQR=interquartile range, S.D.=standard deviation, $A S A=A m e r i c a n$ Society of Anesthesiologists, $S B P=$ systolic blood pressure, HR=heart rate, bpm=beats per minute, RA=regional anesthesia, ENT=ear nose throat, min=minute, IV=intravenous 
Table 2 Univariate analysis of the perioperative risk factors for intraoperative hypothermia

\begin{tabular}{llc}
\hline Variables & Crude HR (95\% Cl) & p-value \\
\hline Age $>60$ years & $1.08(0.57,2.05)$ & 0.814 \\
Sex female & $0.85(0.50,1.46)$ & 0.566 \\
Body mass index $>25 \mathrm{~kg} / \mathrm{m}^{2}$ & $0.67(0.36,1.23)$ & 0.199 \\
Preoperative body temperature $>36^{\circ} \mathrm{C}$ & $1.31(0.47,3.65)$ & 0.597 \\
Preoperative SBP $>140 \mathrm{mmHg}$ & $1.71(0.61,4.73)$ & 0.305 \\
Preoperative heart rate $>80$ beat/min & $0.48(0.28,0.81)$ & 0.006 \\
Type of surgery (Reference: general surgery) & & 0.013 \\
$\quad$ Gynaecology & $0.26(0.09,0.76)$ & 0.119 \\
$\quad$ rrthopaedic & $0.58(0.29,1.15)$ & 0.558 \\
$\quad$ ENT & $0.76(0.31,1.87)$ & 0.066 \\
$\quad$ Others & $0.45(0.19,1.05)$ & 0.827 \\
Duration of operation $>60$ min & $1.06(0.62,1.82)$ & \\
Type of anesthesia (Reference: general anesthesia) & & 0.250 \\
$\quad$ Combined GA and RA & $0.44(0.11,1.81)$ & 0.093 \\
Duration of anesthesia $>60$ min & $1.69(0.92,3.13)$ & 0.277 \\
Intraoperative room temperature $>23{ }^{\circ} \mathrm{C}$ & $1.12(0.92,1.35)$ & 0.429 \\
Unwarmed IV fluid & $1.77(0.43,7.29)$ & \\
\hline
\end{tabular}

$\mathrm{SBP}=$ systolic blood pressure, $\mathrm{ENT}=$ ear nose throat, $\mathrm{min}=$ minute, $\mathrm{GA}=$ general anesthesia, $\mathrm{RA}=$ regional anesthesia, IV=intravenous, $\mathrm{HR}=$ hazard ratio, $\mathrm{Cl}=$ confidence interval

Table 3 Multivariate cox proportional hazards regression model

\begin{tabular}{lll}
\hline Risk factors & HR $(95 \% \mathrm{CI})$ & p-value \\
\hline Preoperative heart rate $>80$ beats/minute & $0.45(0.26,0.77)$ & 0.003 \\
Duration of anesthesia $>60$ minutes & $1.82(0.98,3.38)$ & 0.05 \\
\hline
\end{tabular}

$\mathrm{HR}=$ hazard ratio, $\mathrm{Cl}=$ confidence interval

\section{Discussion}

The incidence of intraoperative hypothermia in our study was $61.5 \%$ which is quite high compared with other studies. ${ }^{1-3}$ We predicted a high incidence due to the cold climate and the geographical setting in our country. Duration of anesthesia more than 60 minutes and preoperative heart rate less than 80 beats per minute were statistically significant risk factors for intraoperative hypothermia in our patients.
These findings were supported by other authors ${ }^{1,3,16}$ who also showed longer duration of anesthesia as a risk factor for intraoperative hypothermia. The rapid decline in the core body temperature in the first hour of operation was due to the vasodilation and redistribution effects of the anesthetic agent used. ${ }^{19,24}$ During anesthesia, it was demonstrated that heat production decreased and cutaneous heat loss increased by $7.0 \% .{ }^{24}$ Prolonged anesthesia also increases the exposure time to a cold operating room and 
is associated with bleeding and increased use of unwarmed intravenous fluids and blood components, all of which can contribute to the development of intraoperative hypothermia. Prewarming in the preoperative period was found to be effective in lowering the incidence of intraoperative hypothermia especially in the first hour of surgery. ${ }^{24-28}$

A study by Kim et al. $^{3}$ revealed that low preoperative heart rate was a risk factor for intraoperative hypothermia. Kasai $\mathrm{T}$ and colleagues ${ }^{17}$ explained that the sympathetic nervous system plays a role in preventing hypothermia. An increased level of catecholamine causes the shunting of heat from the internal organs to the skin. They showed an association of higher preoperative blood pressure and heart rate with a lower incidence of intraoperative hypothermia. However, our study and the study by Kim and colleague ${ }^{3}$ found an association between high preoperative heart rate and a lower incidence of intraoperative hypothermia but could not find an association between high preoperative blood pressure and intraoperative hypothermia.

Although a low preoperative core body temperature, old age, female sex, low body mass index, and open surgical procedures were demonstrated as risk factors for intraoperative hypothermia ${ }^{3,14-21}$, the present study did not find any associations with these factors. These differences might be due to the study population. All of the patients in our study were ASA physical classification 1 or 2 with the majority of patients $(79.1 \%)$ aged $<60$ years. The dress code of the patients during the preoperative period might have influenced the study results. Bhutanese people usually wear warm clothes due to the cold climate until they change into surgical gowns about 1 to 2 hours before entering the operating rooms.

The strength of this study is that we studied multiple risk factors for intraoperative hypothermia. This study also provides baseline data on intraoperative hypothermia in our hospital in Bhutan. The first limitation of this study is our sample size which was possibly not large enough to generate significant associations with all of the risk factors studied. The sample size that was required to find an association between some factors and intraoperative hypothermia was high. The second limitation could be the inclusion of only esophageal temperature measurement in patients having general anesthesia. This possibly led to the high incidence of intraoperative hypothermia in our study.

\section{Conclusions}

Monitoring and maintenance of intraoperative normal core body temperature of patients undergoing surgery is important to prevent the consequences related to intraoperative hypothermia. Patients with preoperative heart rate less than 80 beats per minute and undergoing anesthesia for a duration $>60$ minutes should be assessed from the preoperative period. Furthermore, these patients should be continuously monitored in the intraoperative period to detect intraoperative hypothermia and for early intervention.

\section{Acknowledgement}

Faculty of Medicine, Prince of Songkla University, Thailand including the staff personnel and statisticians at the Epidemiology Unit. Ethics committees of Prince of Songkla University, Thailand and Bhutan for the approval to conduct the study. Staffs and the patients at Jigme Dorji Wangchuck National Referral Hospital, Thimphu, Bhutan where the study was conducted.

\section{Conflict of interest}

None

\section{References}

1. Yi J, Xiang Z, Deng X, Fan T, Fu R, Geng W, et al. Incidence of inadvertent intraoperative hypothermia and its risk factors 
in patients undergoing general anesthesia in Beijing: a prospective regional survey. PLoS One 2015. doi: 10.1371/ journal.pone.0136136.

2. Frisch NB, Pepper AM, Jildeh TR, Shaw J, Guthrie T, Silverton C. Intraoperative hypothermia during surgical fixation of hip fractures. Orthopedics 2016;39:e1170-7.

3. Kim EJ, Yoon H. Preoperative factors affecting the intraoperative core body temperature in abdominal surgery under general anesthesia: an observational cohort. Clin Nurse Spec 2014;28:268-76.

4. Rajagopalan S, Masche E, Na J, Sessler DI. The effects of mild perioperative hypothermia on blood loss and transfusion requirement. Anesthesiology 2008;108:71-7.

5. Schmied H, Kurz A, Sessler DI, Kozek S, Reiter A. Mild hypothermia increases blood loss and transfusion requirement during total hip arthroplasty. Lancet 1996;347:289-92.

6. Bock M, Müller J, Bach A, Böhrer $H$, Martin E, Motsch J. Effects of preinduction and intraoperative warming during major laparotomy. Br J Anaesth 1998;80:159-63.

7. Eberhart LH, Döderlein F, Eisenhardt G, Kranke P, Sessler DI, Torossian A, et al. Independent risk factors for postoperative shivering. Anesth Analg 2005;101:1849-57.

8. Lenhardt R, Marker E, Goll V, Tschernich H, Kurz A, Sessler $\mathrm{DI}$, et al. Mild Intraoperative hypothermia prolongs postanesthetic recovery. Anesthesiology 1997;87:1318-23.

9. National Collaborating Centre for Nursing and Supportive Care Commissioned by National Institute for Health and Clinical Excellence. The management of inadvertent perioperative hypothermia in adults [homepage on the Internet]. London: Royal College of Nursing; 2008 [cited 2018 Aug 21]. Available from: https://www.rcn.org.uk/-/media/royal-college-ofnursing/.../2008/.../pub-003282.pdf

10. American Society of Anesthesiologists. Standards for basic anesthetic monitoring. Committee of origin: standards and practice parameters [homepage on the Internet]. Illinois: ASA; 2015 [cited 2018 Aug 21]. Available from: https:// www.asahq.org/ /media/Sites/ASAHQ/Files/Public/ Resources/standards-guidelines/standards-for-basicanesthetic-monitoring.pdf

11. American Association of Nurse Anesthetists. Standards for nurse anesthesia practice [homepage on the Internet]. Illinois: AANA; 2013 [cited 2018 Aug 21]. Available from: https://www.aana.com/docs/default-source/practice-aana- com-web-documents-(all)/standards-for-nurse-anesthesiapractice.pdf?sfvrsn=e00049b1_2

12. Torossian A, TEMMP (Thermoregulation in Europe Monitoring and Managing Patient Temperature) Study Group. Survey on intraoperative temperature management in Europe. Eur $\mathrm{J}$ Anaesthesiol 2007;24:668-75.

13. Silva $A B$, Peniche Ade C. Perioperative hypothermia and incidence of surgical wound infection: a bibliographic study. Einstein (Sao Paulo) 2014;12:513-17.

14. Wetz AJ, Perl T, Brandes IF, Harden M, Bauer M, Bräuer A. Unexpectedly high incidence of hypothermia before induction of anesthesia in elective surgical patients. J Clin Anesth 2016;34:282-89.

15. Yang L, Huang CY, Zhou ZB, Wen ZS, Zhang GR, Liu KX, et al. Risk factors for hypothermia in patients under general anesthesia: is there a drawback of laminar airflow operating rooms? A prospective cohort study. Int J Surg 2015;21:14-7.

16. de Brito Poveda V, Galvão CM, dos Santos CB. Factors associated to the development of hypothermia in the intraoperative period. Rev Lat Am Enfermagem 2009;17:228-33.

17. Kasai T, Hirose M, Matsukawa T, Takamata A, Yaegashi K, Tanaka Y. Preoperative blood pressure and catecholamines related to hypothermia during general anesthesia. Acta Anaesthesiol Scand 2003;47:208-12.

18. Fernandes LA, Braz LG, Koga FA, Kakuda CM, Módolo NS, de Carvalho LR, et al. Comparison of peri-operative core temperature in obese and non-obese patients. Anaesthesia 2012;67:1364-9.

19. Michiaki Y, Yasuhiro K, Yasuyuki H, Naoki T, Akiyoshi N. Predictive variables of hypothermia in the early phase of general anesthesia. Anesth Analg 2000;90:456-9.

20. Matsukawa T, Sessler DI, Sessler AM, Schroeder. Heat flow and distribution during induction of general anesthesia. Anesthesiology 1995;82:662-73.

21. de Brito Poveda V, Galvão CM, Dantas SAR. Intraoperative hypothermia in patients undergoing elective surgery. Acta Paul Enferm 2009;22:361-6.

22. Torossian A, Van Gerven E, Geertsen K, Horn B, Van de Velde M, Raeder J. Active perioperative patient warming using a self-warming blanket (BARRIER EasyWarm) is superior to passive thermal insulation: a multinational, multicenter, randomized trial. J Clin Anesth 2016;34:547-54.

23. Sessler DI. Temperature regulation and monitoring. In: Miller 
RD, editor. Miller's anesthesia. $7^{\text {th }}$ ed. London: Churchill Livingstone; 2010.

24. Sessler DI, McGuire J, Moayeri A, Hynson J. Isofluraneinduced vasodilation minimally increases cutaneous heat loss. Anesthesiology 1991;74:226-32.

25. El-Gamal N, Elkassabany N, Frank SM, Amar R, Khabar HA, El-Rahmany HK, et al. Age-related thermoregulatory differences in a warm operating room environment (approximately 26 degrees C). Anesth Analg 2000;90:694-8.

26. Horn EP, Bein B, Böhm R, Steinfath M, Sahili N, Höcker J. The effect of short time periods of preoperative warming in the prevention of peri-operative hypothermia. Anaesthesia 2012; $67: 612-7$

27. Torossian A, Brauer A, Hocker J, Bein B, Wulf H, Horn EP. Preventing inadvertent perioperative hypothermia. Dtsch Arztebl Int 2015;112:166-72.

28. Andrzejowski J, Hoyle J, Eapen G, Turnbull D. Effect of prewarming on post-induction core temperature and the incidence of inadvertent perioperative hypothermia in patients undergoing general anaesthesia. Br J Anaesth 2008;101:62731. 